\title{
GAMBARAN CASE BASE MEASLES SURVEILANCE DI KABUPATEN KARAWANG TAHUN 2014
}

\author{
Saleh Budi Santoso \\ District Surveillance Officer of Karawang District Health Office
}

\begin{abstract}
Abstrak : Campak merupakan penyakit yang sangat dimungkinkan untuk dilakukan eradikasi, dengan melalui tahapan reduksi dan eliminasi. Saat ini Indonesia telah mencanangkan tahapan eliminasi campak dengan menerapkan Case Base Measles Surveilance (CBMS) untuk memonitor perkembangan kasusnya. Studi ini bertujuan untuk memberikan gambaran perkembangan penyakit campak khususnya di wilayah Kabupaten Karawang. Desain studi deskriptif dengan analisis deskriptif data Case Base Measles Surveilans Dinas Kesehatan Kabupaten Karawang Tahun 2014. Sebanyak 109 kasus yang tercatat dalam CBMS, 48 kasus $(43,6 \%)$ berhasil dikonfirmasi laboratorium. dengan 24 kasus (48\%) positif campak dan 10 kasus (31\%) positif rubella. Insiden Komulatif kasus campak sebesar 10 case / 1.000 .000 penduduk dengan angka discarded kasus sebesar 4 case $/ 1.000 .000$ penduduk. Kasus campak positif terdistribusi pada kelompok umur 1-4 tahun (45,8\%) dan umur 5-9 tahun (37,5\%). Kasus rubella positif terdistribusi pada kelompok umur 5-9 tahun (85,7\%). 70\% kasus campak positif bergabung dalam kelompok nol dosis dan tidak tahu status imunisasinya. Kabupaten Karawang belum mencapai taraf status eliminasi campak oleh karena angka insidens kasus yang masih tinggi, dengan sebagian besar kasus campak positif tidak diimunisasi. Selain itu, kasus rubella juga menunjukkan proporsi yang tidak sedikit. Kinerja surveilans CBMS dinilai masih belum optimal, mengingat discarded kasus campak masih dibawah 5/1.000.000 penduduk. Peningkatan kinerja surveilans campak harus terus dilakukan dengan melakukan konfirmasi laboratorium kasus campak klinis sebanyak mungkin.
\end{abstract}

Kata Kunci : Case Base Measles Surveillance

\section{CASE BASE MEASLES SURVEILANCE PERFORMANCE IN KARAWANG DISTRICT, 2014}

\author{
Saleh Budi Santoso \\ District Surveillance Officer of Karawang District Health Office
}

\begin{abstract}
Measles eradication is possible to be done, by going through the stages of reduction and elimination. Currently, Indonesia has launched a measles elimination phase by applying the Case Base Measles Surveillance (CBMS). This study aims to provide an overview of the development of measles in Karawang District of Indonesia.Descriptive studies using CBMS Data of Karawang District Health Office in 2014. A total of 109 patients recorded CBMS, 48/109 patient (43.6\%) confirmed by the laboratory, with 24/48 patient (48\%) positive measles and 10/48 patient (31\%) positive rubella, Case Fatality Rate (CFR) $=0 \%$. Cumulative Incidence of measles cases $=10$ per 1,000,000 population, number of discarded $=4$ per 1.000 .000 population.Distributed positive measles patient in the age group 1-4 years (45.8\%) and the age of 5-9 years (37.5\%). Distributed positive rubella cases in the age group 5-9 years (85.7\%). 70\% positive measles patients joined the zero-dose group and do not know their immunization status. Karawang district has not reached the level of measles elimination status, with the majority of positive measles cases were not immunized. Rubella cases also showed an increased proportion. CBMS surveillance performance is still considered optimal, considering discarded measles cases still below 5 / 1,000,000 population. Improved performance of measles surveillance should be carried out by the discovery of cases and laboratory confirmation of clinical measles cases as much as possible.
\end{abstract}

Keywords:

Case Base Measles Surveillance

Korespondensi : Saleh Budi Santoso

Dinas Kesehatan Karawang, Jl. A. Yani No. 1

Karawang

Phone : +62 (0267) 429800

Email : salehsantoso@yahoo.co.id

\section{PENDAHULUAN}

Campak merupakan penyakit yang sangat dimungkinkan untuk dilakukan eradikasi, dengan melalui tahapan reduksi dan eliminasi. Saat ini Indonesia telah mencanangkan tahapan eliminasi campak dengan menerapkan Case Base Measles Surveilance (CBMS) untuk memonitor perkembangan kasusnya. CBMS pertama kali dilakukan di Indonesia mulai tahun 2008 yang diberlakukan secara bertahap, hingga pada tahun 2011 seluruh provinsi menerapkan $\mathrm{CBMS}^{1}$.

Jumlah kasus dengan hasil positif campak terus meningkat, bahkan pada 
rentang tahun 2010-2011: 30\%-45\% kasus yang ditemukan di Indonesia merupakan kasus dengan hasil positif campak $^{2}$. Sedangkan kondisi pelaksanaan CBMS di Kabupaten Karawang pada periode 2011 - 2013 belum secara optimal dan ter-record dengan baik. Oleh karena itu sejak dilakukannya revitalisasi CBMS pada tahun 2014, Puskesmas dan Dinas Kesehatan Kabupaten Karawang secara aktif melakukan CBMS di seluruh sarana pelayanan kesehatan ${ }^{3}$.

\section{METODE PENELITIAN}

Desain studi deskriptif dengan analisis deskriptif data Case Base Measles Surveilans Dinas Kesehatan Kabupaten Karawang Tahun 2014. Data hasil pemeriksaan serologis campak bersumber hasil pemeriksaan oleh Laboratorium
Biofarma Bandung. Kriteria klinis kasus campak yang dilakukan pemeriksaan serologis yaitu: adanya rush kurang dari 21 hari, demam, batuk/pilek disertai atau tidak adanya konjugtivitis. Studi ini bertujuan untuk memberikan gambaran perkembangan penyakit campak khususnya di wilayah Kabupaten Karawang.

\section{HASIL PENELITIAN}

Kasus campak yang terjaring disarana pelayanan puskesmas melalui surveilans CBMS pada tahun 2014 yaitu sebanyak 110 kasus, dengan jumlah kasus diperiksakan spesimennya sebanyak 48 kasus (43,6\%). Proporsi kasus CBMS terbanyak yaitu: kasus campak positif $(50 \%)$ dan kasus rubella (29\%).

Tabel 1. Distribusi Kasus Campak-Rubella dan Capaian Kinerja Surveilans CBMS Dinas Kesehatan Kabupaten Karawang Tahun 2014

\begin{tabular}{|c|c|c|c|c|c|c|c|}
\hline \multirow[b]{2}{*}{ Puskesmas / RS } & \multirow{2}{*}{$\begin{array}{l}\text { Total } \\
\text { Kasus }\end{array}$} & \multirow{2}{*}{$\begin{array}{c}\text { Konfirmasi } \\
\text { Lab }\end{array}$} & \multirow{2}{*}{$\begin{array}{c}\text { Capaian } \\
\text { CBMS }\end{array}$} & \multicolumn{4}{|c|}{ Kriteria Kasus } \\
\hline & & & & $\begin{array}{c}\text { Campak } \\
\text { Klinis }\end{array}$ & $\begin{array}{c}\text { Campak } \\
\text { Positif }\end{array}$ & Negatif & $\begin{array}{c}\text { Rubella } \\
\text { Positif }\end{array}$ \\
\hline RS Intan Barokah & 4 & 0 & 0 & 4 & 0 & 0 & 0 \\
\hline Adiarsa & 3 & 3 & 100 & 0 & 2 & 1 & 0 \\
\hline RSUD Karawang & 2 & 2 & 100 & 0 & 2 & 0 & 0 \\
\hline Ciampel & 3 & 1 & 33,3 & 2 & 0 & 0 & 1 \\
\hline Cikampek & 6 & 0 & 0 & 6 & 0 & 0 & 0 \\
\hline RS Bersalin Sentul & 1 & 1 & 100 & 0 & 1 & 0 & 0 \\
\hline Cilamaya & 4 & 4 & 100 & 0 & 2 & 0 & 2 \\
\hline Jomin & 3 & 0 & 0 & 3 & 0 & 0 & 0 \\
\hline Karawang & 4 & 0 & 0 & 4 & 0 & 0 & 0 \\
\hline Karawang Kulon & 4 & 3 & 75 & 1 & 2 & 0 & 1 \\
\hline Klari & 3 & 0 & 0 & 3 & 0 & 0 & 0 \\
\hline Kotabaru & 1 & 0 & 0 & 1 & 0 & 0 & 0 \\
\hline Krawang Kulon & 2 & 0 & 0 & 2 & 0 & 0 & 0 \\
\hline Lemah Duhur & 2 & 2 & 100 & 0 & 2 & 0 & 0 \\
\hline Majalaya & 3 & 3 & 100 & 0 & 3 & 0 & 0 \\
\hline Nagasari & 14 & 8 & 57,1 & 6 & 3 & 0 & 5 \\
\hline Pakisjaya & 11 & 0 & 0 & 11 & 0 & 0 & 0 \\
\hline Plawad & 13 & 6 & 46,2 & 7 & 1 & 2 & 3 \\
\hline Rawamerta & 5 & 5 & 100 & 0 & 0 & 5 & 0 \\
\hline Rengasdengklok & 3 & 3 & 100 & 0 & 3 & 0 & 0 \\
\hline Sukatani & 6 & 0 & 0 & 6 & 0 & 0 & 0 \\
\hline Tanjung Pura & 2 & 1 & 50 & 1 & 1 & 0 & 0 \\
\hline Telagasari & 7 & 3 & 42,9 & 4 & 0 & 1 & 2 \\
\hline Tirtamulya & 3 & 3 & 100 & 0 & 2 & 1 & 0 \\
\hline Titajaya & 1 & 0 & 0 & 1 & 0 & 0 & 0 \\
\hline Total & 110 & 48 & 43,6 & 62 & 24 & 10 & 14 \\
\hline
\end{tabular}



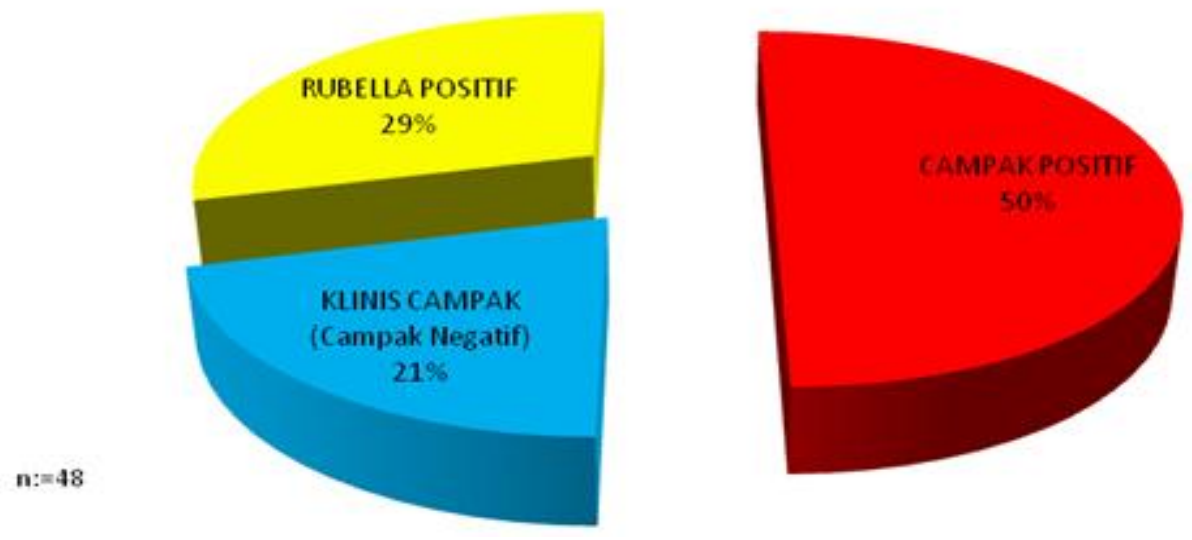

Gambar 1. Proporsi Kasus Campak-Rubella Surveilans CBMS

Dinas Kesehatan Kabupaten Karawang Tahun 2014

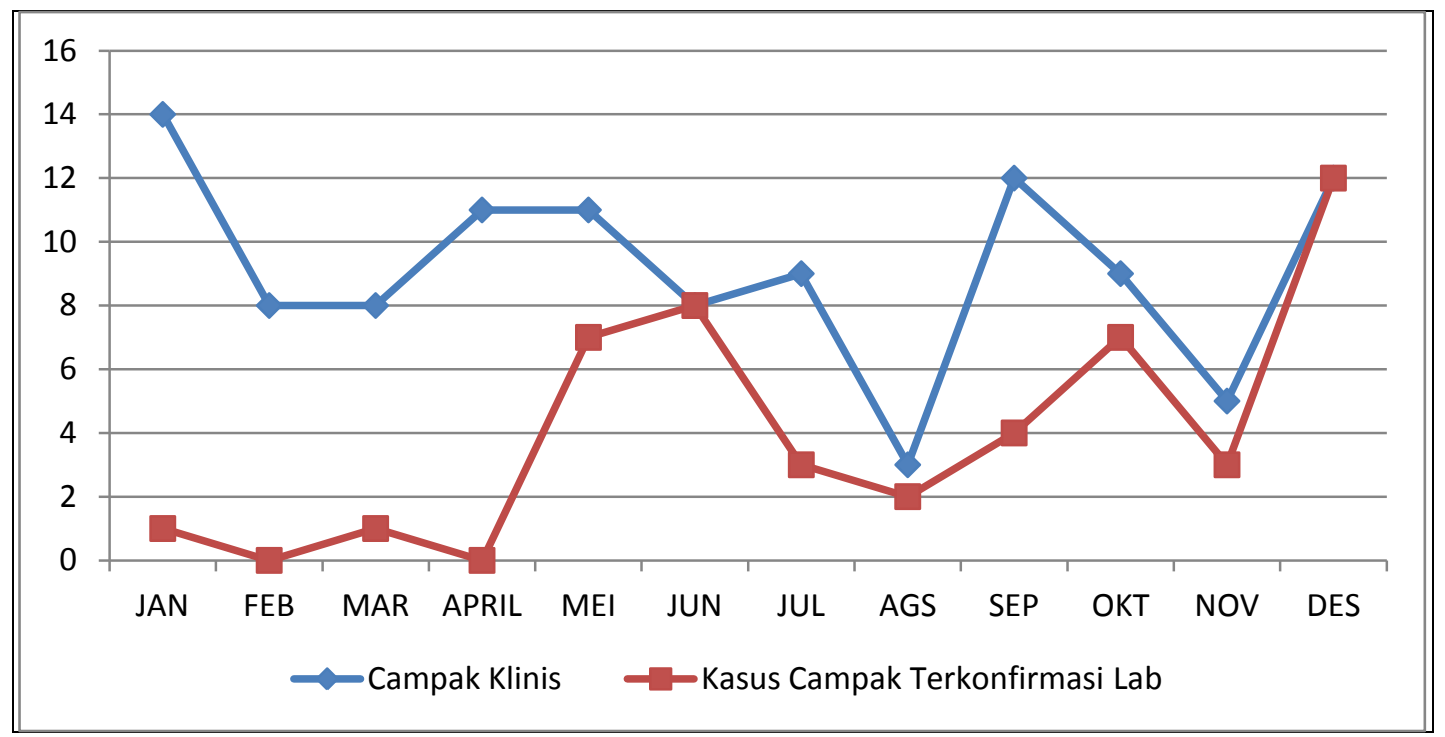

Gambar 2. Grafik Kasus Campak Klinis dan Kasus Campak Terkonfirmasi Laboratorium Dinas Kesehatan Kabupaten Karawang Tahun 2014

Capaian CBMS tertinggi terjadi pada bulan Desember dan Juni 2014, yaitu sebesar $100 \%$ kasus terkonfirmasi laboratorium. Sedangkan pada awal tahun, banyak kasus campak tidak terkonfirmasi oleh laboratorium.

Kelompok umur kasus yang dilaporkan dalam C1 campak terbanyak pada kelompok usia 1- 4 tahun yaitu: sebanyak 43 kasus
$(39,8 \%)$. Begitu pula pada kasus campak positif sebagian besar terdistribusi pada kelompok umur 1-4 tahun, yaitu sebanyak 11 kasus (45,8\%). Sedangkan pada kasus rubella positif, sebagian besar kasus terdistribusi pada kelompok umur $5-9$ tahun sebanyak 12 kasus (85,7\%). 
Tabel 2 Distribusi Kasus Campak-Rubella Berdasarkan Kelompok Umur Dinas Kesehatan Kabupaten Karawang Tahun 2014

\begin{tabular}{|c|c|c|c|c|c|c|c|c|c|}
\hline \multirow{2}{*}{ Usia } & \multicolumn{2}{|c|}{ Campak Klinis } & \multicolumn{2}{|c|}{ Campak Positif } & \multicolumn{2}{|c|}{ Negatif } & \multicolumn{2}{|c|}{ Rubella Positif } & \multirow{2}{*}{ Total $^{*}$} \\
\hline & $\begin{array}{c}\text { Jumlah } \\
\text { Kasus }\end{array}$ & $\%$ & $\begin{array}{c}\text { Jumlah } \\
\text { Kasus }\end{array}$ & $\%$ & $\begin{array}{c}\text { Jumlah } \\
\text { Kasus }\end{array}$ & $\%$ & $\begin{array}{c}\text { Jumlah } \\
\text { Kasus }\end{array}$ & $\%$ & \\
\hline$<1$ th & 6 & 10,0 & 1 & 4,2 & 3 & 30,0 & 0 & 0 & 10 \\
\hline $1-4$ th & 30 & 50,0 & 11 & 45,8 & 1 & 10,0 & 1 & 7,1 & 43 \\
\hline $5-9$ th & 14 & 23,4 & 9 & 37,5 & 3 & 30,0 & 12 & 85,8 & 38 \\
\hline $10-14$ th & 5 & 8,3 & 2 & 8,3 & 3 & 30,0 & 1 & 7,1 & 11 \\
\hline$>15$ th & 5 & 8,3 & 1 & 4,2 & 0 & 0 & 0 & 0 & 6 \\
\hline Total & 60 & 100 & 24 & 100 & 10 & 100 & 14 & 100 & 108 \\
\hline
\end{tabular}

Tabel 3. Distribusi Kasus Campak-Rubella Berdasarkan Status Imunisasi Dinas Kesehatan Kabupaten Karawang Tahun 2014

\begin{tabular}{|c|c|c|c|c|c|}
\hline \multirow{2}{*}{ Kriteria Kasus } & \multicolumn{4}{|c|}{ Status Imunisasi Campak } & \multirow{2}{*}{ Total } \\
\hline & 0 kali & 1 kali & 2 kali & Tidak Tahu & \\
\hline Campak Klinis & 5 & 18 & 1 & 38 & 62 \\
\hline Campak Positif & 7 & 4 & 3 & 10 & 24 \\
\hline Negatif & 2 & 6 & 1 & 1 & 10 \\
\hline Rubella Positif & 3 & 6 & 4 & 1 & 14 \\
\hline Total & 17 & 34 & 9 & 50 & 110 \\
\hline
\end{tabular}

Status imunisasi campak pada kasus yang dilaporkan dalam surveilans CBMS yaitu: sebagian besar kasus (45 \%) tidak mengatahui secara pasti berkaitan dengan status imunisasi campak putra/putrinya. Sebagian besar kasus campak positif yaitu tidak mendapatkan imunisasi campak, yaitu sebanyak 7 kasus (29\%) dan tidak jelas status imunisasinya sebanyak 10 kasus (41\%). Sedangkan status imunisasi campak pada kasus rubella positif, sebagian besarnya telah mendapatkan imunisasi campak sebanyak 1 kali $(42 \%)$ atau 6 kasus.

\section{PEMBAHASAN}

Hasil CBMS menunjukkan kasus campak positif menempati proporsi terbanyak, begitupula distribusi kasus rubella yang mulai bermunculan. Bila dibandingkan dengan data tahun 2013 maka terjadi peningkatan kegiatan CBMS sebesar 100\%. Hal ini dikarenakan kegiatan CBMS pada tahun sebelumnya belum berjalan optimal.

Perhitungan angka kejadian kasus campak Kabupaten Karawang mencapai 11 per 1 juta penduduk, sedangkan syarat tercapainya kondisi eliminasi campak yaitu $<5$ kasus per 1 juta penduduk). Sedangkan perhitungan angka discarded kasus campak mencapai: 4 per 1 juta penduduk (target : > 5 kasus campak negative per 1 juta penduduk). Perhitungan populasi balita rentan campak juga menunjukkan angka yang sama dengan jumlah kohort balita pada tahun 2014. Gambaran ini menunjukkan bahwa kasus campak masih banyak tersebar di masyarakat dan kemungkinan terjadinya KLB campak dibeberapa daerah rentan.

Permasalahan berkaitan dengan pelaksanaan CBMS diantaranya: tidak adanya data pembanding capaian/ gambaran distribusi kasus CBMS tahun 
2013, petugas terlambat melaporkan kasus campak, kasus tidak diambil specimen darahnya, pengisian data format C1 campak tidak lengkap terutama pada indikator data penting, minimnya sosialisasi antar unit pelayanan di Puskesmas/RS berkaitan dengan program CBMS.

\section{KESIMPULAN DAN SARAN}

Kabupaten Karawang belum mencapai target eleminasi campak karena angka kejadian kasus campak mencapai 11 per 1 juta penduduk. Respon surveilans yang harus dilakukan: meningkatkan kelengkapan dan ketepatan laporan, konfirmasi/mencari kasus baru campak/rubella sekitar tempat tinggal/ sekolah kasus awal berada, mengupayakan pengambilan specimen darah setiap kasus campak yang datang ke unit pelayanan kesehatan, meningkatkan jejaring surveilans intra dan ekstra unit pelayanan serta meningkatkan kinerja mutu cakupan imunisasi campak.

\section{DAFTAR PUSTAKA}

1. Kementerian Kesehatan RI ( 2012): Data Surveilans dan KLB 2011. Jakarta

2. Kementerian Kesehatan RI (2012): Petunjuk Teknis Surveilans Campak. Jakarta

3. Dinas Kesehatan Kabupaten Karawang (2014): Laporan Tahunan Imunisasi. Karawang 